\title{
Yoga as Therapy-Therapy as Yoga
}

\author{
Paul Macneill* \\ University of Sydney, Sydney Health Ethics, Australia
}

Submission: August 24, 2018; Published: August 27, 2018

*Corresponding author: Paul Macneill, University of Sydney, Faculty of Medicine and Health, Sydney Health Ethics, Sydney, Australia; Tel: +612.9036.3405; Email: paul.macneill@sydney.edu.au

\section{Opinion}

In this essay I explore a relationship between 'yoga' and 'therapy' as each of these two words are commonly understood. I then explore a more intrinsic relationship between the two, that draws on the essence of both yoga and therapy.

What is usually understood by 'yoga,' or 'hatha yoga,' in the West is found in the kind of class you would expect in any yoga school-and even in the local gym. Typically, a yoga session includes (at least some) postures or asana including standing postures; inverted poses (hand stands, head stands, and shoulder stands); forward bends, twists, and backbends; and at least one restorative pose (such as shavasana) to complete a session. In practicing asana, movements are usually coordinated with the breath. A practice session may also include pranayama and meditation. ${ }^{1}$ Commonly, one leaves a class feeling relaxed, and restored in both a physical and psychological sense. In this sense, yoga is therapeutic.

'Therapy' has a couple of common meanings: "The ... treatment of disease; curative medical or psychiatric treatment," and, "secondly," "As the the final element in words denoting treatment by means expressed in the first element" which, of course, includes "physiotherapy."2 As with a yoga session, following a session of therapy, of whatever kind, one is typically relieved-at least to some extent-of the pain or discomfort that prompted a visit to the therapist in the first place.

Clearly there is an overlap between the two in that a session of yoga, or therapy, leaves the practitioner/client in a better state. One way to conceptualize this is that yoga is one form of therapy amongst many-a subset encompassed within the broader class of therapy in general. In this sense yoga is therapeutic. Understanding a relationship between yoga and therapy in this way is not new. In a more explicit sense, yoga can address particular ailments and injuries as a means of therapy. For example, in Iyengar schools, teachers are trained in 'medicinal yoga.' Iyengar yoga is described as a system that cultivates "strength, flexibility, stability, and awareness, and can be therapeutic for specific conditions. ${ }^{3}$ A teacher may treat a physical injury in a student by choosing particular yoga postures, that relate to the injured area in the body, with the aim of engendering alignment, flexibility, and stability. Teachers from other traditions have similarly claimed that yoga is effective "in preventing or managing" a number of conditions including "back pain, arthritis, diabetes, asthma, hypertension, allergies, digestive disorders ... depression, anxiety, fear and such other common ailments." More generally, medicinal yoga is seen as empowering "its practitioners to progress toward good health and well-being by helping to reduce symptoms, restore balance, and increase vitality." ${ }^{4}$

However, I want to take a deeper approach and consider both yoga and therapy in their inherent functions as relief from suffering. Both of them address suffering. What is sometimes overlooked by students of yoga is that yoga is fundamentally about overcoming suffering. An ancient text of yoga-Patanjali's Yoga Sutras-states (in Sutra 2:2) that the objective of yoga is 'to induce' self-luminous joy (samadhi). As Patanjali makes clear in his Yoga Sutras, it is ignorance that blocks our experience of this natural state of joy. This reference to ignorance needs closer attention-and Patanjali goes right to the heart of ignorance. The predominant form of ignorance is described in Sutra 2:3 as "the false sense of self-identity." ${ }^{5}$ Our self-identity is a composite: it comprises the things we like or dislike; our memories, anticipations of the future, our desires, fears and anxieties. It helps to see the self as a collection of attributes in this way. We mistakenly assume that the 'self' is a single thing that has an independent existence in the world. Yoga however

${ }^{1}$ Macneill Paul (2011) Yoga and Ethics: The Importance of Practice. In: Stillwaggon Swan L (Ed), Yoga-Philosophy for Everyone, Wiley-Blackwell, Oxford, UK, pp: 187-199.

${ }^{2}$ Oxford English Dictionary.

${ }^{3}$ Yoga Journal, Iyengar Yoga.

${ }^{4}$ Jogendra Bhagat, Yoga Solutions.

${ }^{5}$ Tigunait, Pandit Rajmani (2017) The Practice of the Yoga Sutra: Sadhana Pada, Himalayan Institute Press, Pennsylvania, USA, p: 22. 
teaches that 'the self' derives primarily from an idea that we comprise our bodies and minds. It is a limited understanding of ourselves that ignores the very real experience of being which is far more extensive than 'my' body and 'my' mind. This limited idea of ourselves, contained within a body, leads to constant efforts to sustain and protect 'ourselves' so that we can endure in the world, and against all those other entities and forces that threaten our existence.

To put it simply, the Yoga Sutras teach that we take the idea of 'me' and 'mine' way to seriously and get caught up in the drama of 'my' self. From the perspective of 'my' self, we fail to see things as they are. We function from a place of fear and anxiety, driven by a need to protect ourselves, to seek out the things that give us pleasure, and to avoid those things that may bring pain. In other words, we approach the world from a focus-the world seen through the lens of 'my' wants and fears. This inevitably leads to suffering.

Buddhism also is fundamentally about recognizing suffering and becoming free from it. The Dalai Lama was asked recently 'What can you do when you have negative thoughts and emotions?" His answer is a beautiful and succinct summation of yoga and Buddhism! He said that negative thoughts and emotions are to do with two things: a self-centered attitude (“I, I, I, my, my, my, like that!"). And secondly, "We accept reality as it appears." Although, in this brief exchange, he did not elaborate on his second observation, it is clear from a Buddhist (and yogic) perspective, that this 'reality'-the appearance that we take as real-is distorted. We see reality through a prism of 'myself.' Reality, through this prism, is always 'about me.' The beauty of the Dalai Lama's observations is in their simplicity. We suffer because we are obsessed with 'myself' and this obsession leads to several afflictions including a distorted view of reality. Pantanjali, in his Yoga Sutras, spells out these afflictions in considerable detail.

To this extent, yoga and Buddhism are not belief systems. They are descriptive of human beings as they are-as they typically function. With some training, we can begin to observe ourselves and recognize that this is indeed what happens in our own minds. Both yoga and Buddhism offer empirical and testable observations. However-like any form of research-we need some training to be capable of confirming observations within ourselves about the way human beings typically function. ${ }^{7}$ This is a form of empiricism, in which we turn our focus toward our own thoughts and emotions. The capacity to observe how we think and feel is developed through training our attention toward our own subjective experience. It leads to observations of our own thought processes and to recognitions of the way in which these limit our experience of life. Once we begin to see these limitations, we naturally realise that we could live with more freedom. Recognitions of this kind support a practice aimed at overcoming obstacles to our own freedom. The power of these recognitions can be profound! For example, if I observe that I immediately go on the defense when someone criticizes me, that recognition gives me a possibility of responding differently. I don't need to defend 'myself.' I may be open to learning from the criticism. That is liberating. Alternatively, it may be that the person criticizing me is herself tormented by a judgmental tendency, and-if I am open and unencumbered-I can see that and have some compassion for her.

Recognizing that I am encumbered leads to a desire to live more freely, less constrained by my fears and anxieties, and by my constant desires. Witnessing, within myself, how these 'afflictions' constrain me is potentially liberating. Each recognition can be an 'Ah hah!' moment: "So that's what I do!" This is liberating, because the need to step out of those constraints-so that I can live more freely-becomes obvious. This is therapy. Understood in this deeper sense, all therapy is ultimately a means to living joyfully. This is to turn my (above) observation around-that yoga is a subset of therapy-and claim that therapy is a subset of yoga.

To the extent that I can follow simple practices-like not getting caught up in the drama of 'myself'-I can move toward constancy, and steady happiness, less suffering, less disturbing drama, and occasional joy. These very real daily affirmations of yoga as a practice, embolden me to accept the possibility that life could be lived within a much more expansive experience. With each step I gain confidence. I also gain more trust in those teachers of yoga who have gone before me and found freedom within themselves. I am more and more open to accept (for example, from Patanjali and from the Dalai Lama) that as 'Paul' diminishes in importance-as I give Paul and his silly (sometimes nasty) prejudices and pressing needs, less importance-something much more satisfying comes into the space that Paul and his big ego takes up. Yoga is therapy in a more profound sense than relief from injuries and pains. It is a path to experiencing selfluminous joy (samadhi) regardless of the dramas going on in my life.

My contention is that this deeper understanding of both yoga and therapy provides a goal within which the conventional understanding of yoga as therapy makes sense. Not all students are ready or able to approach yoga as a path to joy. When one is caught up in a tight and restricted body, experiencing pain from physical and psychological injuries, it may take some time to gain confidence that yoga, as therapy, can begin to de-stress our over-wrought systems. However, as this begins to happenas we experience an opening within ourselves-we are more amenable to a deeper realization that is afforded by yoga. My own drama, and the importance I give to it, is a form of ignorance

${ }^{6}$ His Holiness, the Dalai Lama. Dealing with Negative Emotions (2018)

${ }^{7}$ Alan Wallace, Exclusive interview. Science \& Nonduality. 
that eclipses-in the way the moon eclipses the sun-the natural joy that is inherent in me. The simple joy of being is the same joy that I see in a child. It is still there in me but eclipsed by the importance I give to 'myself.' This notion of 'me' is a form of ignorance that a wise and experienced yoga therapist can assist me to become free from.

Your next submission with Juniper Publishers
will reach you the below assets
- Quality Editorial service
- Swift Peer Review
- Reprints availability
- E-prints Service
- Manuscript Podcast for convenient understanding
- Global attainment for your research
- Manuscript accessibility in different formats
( Pdf, E-pub, Full Text, Audio)
- Unceasing customer service
Track the below URL for one-step submission
https://juniperpublishers.com/online-submission.php

